\title{
Effect of Bacillus amyloliquefaciens and Bacillus subtilis on fermentation, dynamics of bacterial community and their functional shifts of whole-plant corn silage
}

Jie Bai ${ }^{1,2}$, Marcia Franco ${ }^{3}$, Zitong Ding ${ }^{1,2}$, Lin Hao ${ }^{4}$, Wencan Ke ${ }^{1,2}$, Musen Wang ${ }^{1,2}$, Dongmei Xie ${ }^{1,2}$, Ziqian Li $i^{1,2}$, Yixin Zhang ${ }^{1,2}$, Lin $\mathrm{Ai}^{5}$ and Xusheng Guo $0^{1,2^{*}}$ (1)

\begin{abstract}
Background: Bacillus amyloliquefaciens (BA) and Bacillus subtilis (BS) are usually used as feed supplements directly or bacterial inoculants in biological feeds for animals. However, few research have reported the effects of BA and BS on fermentation characteristics and bacterial community successions of whole-plant corn silage during ensiling. If the BA and BS inoculants have positive effects on silages, then they could not only improve fermentation characteristics, but also deliver BA or BS viable cells to ruminants, which would play its probiotic effect. Therefore, the objectives of this study were to investigate the effects of BA and BS on the fermentation, chemical characteristics, bacterial community and their metabolic pathway of whole-plant corn silage.

Results: Freshly chopped whole-plant corn was inoculated without or with BA and BS, respectively, and ensiled for 1, 3, 7, 14 and $60 \mathrm{~d}$. Results showed that BA and BS inoculations increased lactic acid concentrations of whole-plant corn silages compared with control, and BA inoculation decreased acetic acid concentrations, whereas BS inoculation decreased fiber contents and increased crude protein (CP) content. Higher water-soluble carbohydrate contents and lower starch contents were observed in BA- and BS-inoculated silages compared with that in control. The decreased CP content and increased non-protein nitrogen content were observed in BA-inoculated silage, which was consistent with the higher amino acid metabolism abundances observed in BA-inoculated silage. In addition, it was noteworthy that BA and BS inoculations increased the metabolism of cofactors and vitamins, and decreased the relative abundances of drug resistance: antimicrobial pathways. We also found that the bacterial metabolism pathways were clearly separated into three clusters based on the ensiling times of whole-plant corn silage in the present study. There were no significant differences in bacterial community compositions among the three groups during ensiling. However, BA and BS inoculations decreased the relative abundances of undesirable bacteria such as Acetobacter and Acinetobacter.
\end{abstract}

\footnotetext{
* Correspondence: guoxsh07@|zu.edu.cn

'State Key Laboratory of Grassland Agro-ecosystems, School of Life Sciences,

College of Pastoral Agriculture Science and Technology, Lanzhou University, Lanzhou 730000, China

${ }^{2}$ Probiotics and Biological Feed Research Centre, Lanzhou University, Lanzhou 730000, China

Full list of author information is available at the end of the article
}

(c) The Author(s). 2022 Open Access This article is licensed under a Creative Commons Attribution 4.0 International License, which permits use, sharing, adaptation, distribution and reproduction in any medium or format, as long as you give appropriate credit to the original author(s) and the source, provide a link to the Creative Commons licence, and indicate if changes were made. The images or other third party material in this article are included in the article's Creative Commons licence, unless indicated otherwise in a credit line to the material. If material is not included in the article's Creative Commons licence and your intended use is not permitted by statutory regulation or exceeds the permitted use, you will need to obtain permission directly from the copyright holder. To view a copy of this licence, visit http://creativecommons.org/licenses/by/4.0/ The Creative Commons Public Domain Dedication waiver (http://creativecommons.org/publicdomain/zero/1.0/) applies to the data made available in this article, unless otherwise stated in a credit line to the data. 
Conclusion: Our findings suggested that the BS strain was more suitable as silage inoculants than the BA strain in whole-plant corn silage in this study.

Keywords: Bacillus silage inoculants, Function prediction, Silage quality, Zea mays

\section{Introduction}

Whole-plant corn silage, which makes up over $40 \%$ of forage fed to dairy cows [1], has become the main roughage used in ruminants' diet especially for dairy cattle diets worldwide. Hence, nutrionally and hygiencially high-quality silage is a crucial preprequisite for developing ruminant husbandary. To produce high quality silage, silage inoculants are usually used to promote fermentation process. In the report of $\mathrm{Xu}$ et al. [2], silage inoculants were divided into four generations according to their different functions during ensiling. Homolactic bacteria, accelerating the lactic acid fermentation and improving the fermentation quality and nutrients preservation of silage, were identified as the first generation inoculants. Heterolactic bacteria, improving aerobic stability by producing acetic acid and 1, 2-propanediol, were subsequently identified as second generation inoculants. Some strains with special functions, such as feruloyl esterases-producing Lactobacillus plantarum [3] or Pediococcus acidilactici with high-antioxidant activity [4] that improved the digestibility of fiber or antioxidant capacity in silages, were defined as third generation inoculants. Directly fed microbes, such as Saccharomyces cerevisiae, were defined as fourth generation silage inoculants where probiotic microbes delivered direct benefits to the animals through silages. Bacillus could also be classified as fourth generation silage inoculants because of its favorable ability to improve animal performance when orally administered [5] and improve fermentation quality and aerobic stability in alfalfa silages [6].

Bacillus amyloliquefaciens and Bacillus subtilis are usually used as biological control agents to protect plants effectively against plant pathogens $[7,8]$. In addition, due to the antimicrobial ability of $B$. amyloliquefaciens and B. subtilis, they are used as feed supplements directly or bacterial inoculants in biological feeds for monogastric animals, such as poultry and pigs [911]. There are also some studies reported the application of $B$. subtilis in silages. Lara et al. [12] and Bai et al. [6] found that B. subtilis used in silages improved fermentation quality and inhibited aerobic spoilage. However, few research have reported the effects of B. amyloliquefaciens on fermentation characteristics in silages. Sansinenea and Ortiz [13] reported that B. amyloliquefaciens was related to B. subtilis and had the potential to produce many antimicrobial compounds. Thus, we speculated that B. amyloliquefaciens could also improve fermentation characteristics of silages and deliver $B$. amyloliquefaciens viable cells to ruminants.

Understanding the succession of bacterial community could provide deep insight into the fermentation process underlying silage formation. The bacterial community succession at different phases of ensiling is a dynamic process that varies throughout the fermentation period, and single-molecule real-time (SMRT) sequencing technologies provide useful information on microbial shifts at the species level [14]. In addition, the potential functions of bacterial communities were predicted in some studies, such as Zhang et al. [15] and Bai et al. [16], where they found that the main bacterial functions could explain the material conversion during the composting or ensiling process. To date, the effects of lactic acid bacteria (LAB) inoculants on bacterial community diversity and succession of silages using SMRT sequencing technology have been evaluated in previous studies [16, 17]. LAB, as a commonly used silage inoculants, have been studied a lot in alfalfa silages. However, few researches have reported the effects of B. amyloliquefaciens or B. subtilis on bacterial community succession and their functional shifts in whole-plant corn silage. Therefore, the objective of this study was to investigate the effects of $B$. amyloliquefaciens or B. subtilis on the fermentation characteristics, bacterial community succession and their functional shifts of whole-plant corn silage during ensiling.

\section{Materials and methods Silage preparation}

Whole-plant corn (Zea mays L. Dajingjiu 3876) was harvested at half milk-line from 4 randomly selected sites in a commercial farm located in Dingxi city, Gansu province, China. The whole-plant corn was chopped into 2 $\mathrm{cm}$ size by using a forage cuter (Toyohira Agriculture Machinery, Sapporo, Japan) and then taken into the laboratory immediately. For each of the 4 randomly selected sites, there were 15 piles of forage ( 1 untreated pile and 2 inoculated piles for each fermentation time of $1,3,7,14$ and $60 \mathrm{~d}$ ). The corn forage piles were treated separately with distilled water (control, CK); Bacillus amyloliquefaciens $\mathrm{HRH}_{317}$ (BA, $1 \times 10^{6}$ colony-forming unit/g fresh matter, provided by Shanxi Agricultural University, China), which could inhibit fungus by producing antifungal proteins [18]; Bacillus subtilis CP7 (BS, $1 \times 10^{6}$ colony-forming unit/g fresh matter, provided by Zhangye Aolin Beier Biological Technology Co., Ltd., 
China), which had the ability to inhibit gram-negative bacteria, such as Escherichia and Salmonella by producing antibacterial peptides [6]. The whole-plant corn forage treated with inoculants was then packed into vacuum-sealing polyethylene plastic bags and vacuumsealed. Each of the groups was ensiled using 4 replicates per group with approximately $300 \mathrm{~g}$ of forage per bag. The whole-plant corn silage bags were stored at room temperature $\left(25 \pm 2{ }^{\circ} \mathrm{C}\right)$ and sampled after $1,3,7,14$ and $60 \mathrm{~d}$ of ensiling period.

\section{Fermentation characteristics and chemical compositions analyses}

Twenty g of each fresh and ensiled sample was put in a juice extractor and squeezed with $180 \mathrm{~mL}$ distilled water for $30 \mathrm{~s}$, and then filtrated through four layers of cheesecloth. The filtrate $\mathrm{pH}$ was measured using a glass electrode $\mathrm{pH}$ meter. Determination methods of lactic, acetic, and propionic acid concentrations were referenced by the description of Zhang et al. [4]. Chemical compositions of silages at $60 \mathrm{~d}$ of ensiling period were performed as described below. The determination methods of contents of non-protein nitrogen (NPN), ammonia nitrogen $\left(\mathrm{NH}_{3}-\mathrm{N}\right)$, and water-soluble carbohydrate (WSC) were referenced by the description of Licitra et al. [19] and Ke et al. [20]. The chemical compositions of silages were presented based on their dry matter (DM) base. The DM content of samples $(100 \mathrm{~g})$ was measured by drying them at $65^{\circ} \mathrm{C}$ for $72 \mathrm{~h}$, and then ground with a mill $(1$ $\mathrm{mm}$ screen) for nutritional composition analyses [20]. The determination methods of crude protein $(\mathrm{CP})$, neutral detergent fiber (aNDF) and acid detergent fiber (ADF) contents were referenced according to AOAC [21] and van Soest [22]. The starch content of each sample was determined and corrected for free glucose using a total starch determination kit (Bray Bussiness Park, Bray, Co. Wicklow, A98 YV29, Ireland).

\section{Microbial composition using SMRT analyses}

Total genomic DNA of surface bacteria of fresh and ensiled whole-plant corn from the three groups fermented for $1,3,7,14$, and $60 \mathrm{~d}$ were extracted using a DNA isolation kit (Tiangen, DP302-02, Tiangen, China). Among the four replicates of each treatment, three replicated samples were randomly chosen for DNA extraction. The quality and quantity of extracted DNAs were measured according to the description of Guo et al. [14]. The PCR (Polymerase Chain Reaction) amplification of the bacterial fulllength 16S rRNA genes was performed using the forward primer 27F (5'-AGRGTTYGATYMTGGC TCAG-3') and the reverse primer 1492R (5'-RGYT ACCTTGTTACGACTT-3'). Sample-specific 16-bp barcodes were incorporated into the primers for multiplex sequencing. The PCR amplicons were purified with Agencourt AMPure beads (Beckman Coulter, Indianapolis, IN, USA) and quantified using the PicoGreen dsDNA Assay kit (Invitrogen, Carlsbad, CA, USA). The sample was then used to generate a library by using SMRTbell Template Prep Kit 1.0SPv3, and sequencing was performed using the PacBio platform with DNA/Polymerase Binging Kit 3.0 (PacBio) at Wuhan Frasergen Bioinformatics Co, Ltd. (Wuhan, China).

The rdp_classifier-2.2 software was used to annotate the species of OTU representative sequence basing the database of SILVA 138 firstly. For those OTU representative sequences that annotated to the genus levels but not to the species levels, such as Lactobacillus, Weissella, Leuconostoc and Pedicoccus, the blastn (blast-2.11.0+) program based on the best hit method was further used to assign the annotations to the species level by depositing the data in the SILVA 138 library [23, 24]. Before the follow-up statistical analysis, unknown species were filtered at each species level (genus and species), and the abundance of filtered species was classified into others. The communities or species that have significant differences among the three groups were calculated using the linear discriminant analysis effect size analysis (LEfSe). Bacterial function prediction was proof checked from the Kyoto Encyclopedia of Genes and Genomes (KEGG) database using Phylogenetic Investigation of Communities by Reconstruction of Unobserved States (PICRUSt2), which predicts the functional abundance of samples based on the abundance of marker gene sequences in the sample [25].

\section{Statistical analysis}

The experimental protocol had a $3 \times 5$ factorial design with 3 inoculants and 5 ensiling times. The data for $\mathrm{pH}$ and organic acids were analyzed using the general linear model procedure of the Statistical Package for Social Science (SPSS 21.0, SPSS, Inc., Chicago, IL) according to the model:

$$
Y_{i j}=\mu+T_{i}+D_{j}+(T \times D)_{i j}+\varepsilon_{i j}
$$

where $Y_{i j}$ represents the response variable, $\mu$ is the overall mean, $T_{i}$ is the effect of inoculants, $D_{j}$ is the effect of ensiling time, $(T \times D)_{i j}$ is the effect of the interaction between the inoculants and ensiling time, and $\varepsilon_{i j}$ is the random residual error. Chemical compositions of $60-\mathrm{d}$ silage samples were analyzed using one-way ANOVA. Tukey's test was also used for pair-wise mean comparisons. Significance was considered at $P<0.05$. 


\section{Results}

Chemical compositions of whole-plant corn forage before ensiling

The chemical compositions of fresh whole-plant corn are presented in Table 1. The DM content of the wholeplant corn was $291 \mathrm{~g} / \mathrm{kg}$ of fresh weight (FW). The starch content was $107 \mathrm{~g} / \mathrm{kg}$ DM, CP content was $78.6 \mathrm{~g} /$ $\mathrm{kg}$ DM, $\alpha \mathrm{NDF}$ content was $494 \mathrm{~g} / \mathrm{kg}$ DM, ADF content was $266 \mathrm{~g} / \mathrm{kg} \mathrm{DM}$, and WSC content was $273 \mathrm{~g} / \mathrm{kg} \mathrm{DM}$.

\section{Fermentation characteristics and chemical compositions of whole-plant corn silage}

Fermentation characteristics and chemical compositions of whole-plant corn silages are listed in Tables 2 and 3, respectively. Overall, the $\mathrm{pH}$ of the three groups decreased rapidly and kept stable after $3 \mathrm{~d}$ of ensiling. The concentrations of lactic and acetic acids in the three silage groups increased with the extension of the ensiling period (Table 2). The highest lactic acid concentration was observed in BA-inoculated silage, and the lactic acid concentration of BS-inoculated silage was higher than that in control during the entire ensiling period $(P<$ 0.001). The acetic acid concentration was higher in BAinoculated silage compared with control after 1, 3, and 7 $\mathrm{d}$ of ensiling, while decreased after 14 and $60 \mathrm{~d}$ of ensiling period. The higher acetic acid concentration was in BS-inoculated silage compared with control at the ensiling stages of 1 to $14 \mathrm{~d}(P<0.001)$, and no differences were observed after $60 \mathrm{~d}$ of ensiling period. Higher lactic acid/acetic acid (LA/AA) ratios were observed in BAand BS-inoculated silages than that in control after 1, 3, 7 , and $14 \mathrm{~d}$ of ensiling period, and the lowest LA/AA ratio was observed in BA-inoculated silage after $60 \mathrm{~d}$ of ensiling $(P<0.001)$. No propionic acid was detected in all whole-plant corn silages during the ensiling period.

The BA and BS inoculations increased WSC contents and decreased starch contents when compared with control $(P<0.05$, Table 3$)$. The highest $\mathrm{CP}$ content was observed in BS-inoculated silage, followed by control, and then in BA-inoculated silage $(P<0.001)$. On the other

Table 1 Chemical composition of whole-plant corn forage before ensiling

\begin{tabular}{ll}
\hline Items & Whole-plant corn \\
\hline DM, g/kg FW & 291 \\
WSC, g/kg DM & 273 \\
Starch, g/kg DM & 107 \\
CP, g/kg DM & 78.6 \\
aNDF, g/kg DM & 494 \\
ADF, g/kg DM & 266 \\
\hline
\end{tabular}

$D M$, dry matter; $F W$, fresh weight; $W S C$, water soluble carbohydrates; $C P$, crude protein; $a N D F$, neutral detergent fiber assayed with a heat stable amylase and expressed inclusive of residual ash; $A D F$, acid detergent fiber expressed inclusive of residual ash hand, the highest NPN content was in BA-inoculated silage, followed by control, and then in BS-inoculated silage $(P<0.001)$. However, no differences were observed in $\mathrm{NH}_{3}-\mathrm{N}$ contents among the three groups. The aNDF and ADF contents were lower in BS-inoculated silage compared with control and BA-inoculated silage $(P<$ $0.05)$.

\section{Bacterial community composition and diversity in whole- plant corn silage}

Bacterial diversity, bacterial community compositions and differences are shown in Fig. 1 and 2, respectively. The alpha diversities were lower in BA- and BSinoculated silages compared with control after 1 and $3 \mathrm{~d}$ of ensiling period. However, the alpha diversity was lower in control after 7, 14, and $60 \mathrm{~d}$ of ensiling period (Fig. 1A). According to the beta diversity (PCoA, Principal Coordinates Analysis), significant differences and regular changes in bacterial community successions at the different fermentation stages were observed. Nevertheless, the bacterial communities in the three groups were not clearly separated (Fig. 1B). The bacterial community dynamics of whole-plant corn silages at the genus and species level are shown in Fig. $1 \mathrm{C}$ and D, respectively. Before ensiling, the main epiphytic bacteria at the genus level were Weissella and Leuconostoc, and Gluconobacter, Serratia, Pantoea, and Lactococcus also had higher relative abundance. The main epiphytic bacterial species are Weissella cibaria (20.92\%) and Leuconostoc pseudomesenteroides (9.51\%). After ensiling, the bacterial community compositions of the three silage groups were similar, and obvious regular changes were observed with the extension of ensiling. The relative abundance of Lactobacillus increased rapidly, and Weissella, Leuconostoc, and Gluconobacter decreased during the fermentation process. After $60 \mathrm{~d}$ of ensiling, the compositions of dominant bacteria at genus levels became simple that Lactobacillus was the main genus, and Lactococcus appeared in the three silage groups, and Lactococcus was higher in the BA inoculated silage. In addition, the species of Lactobacillus varied during the ensiling. After $60 \mathrm{~d}$ of ensiling, the bacterial community compositions at the species level were completely changed. The dominant Lactobacillus changed from $L$. brevis (> 30\%) after 7 and $14 \mathrm{~d}$ of ensiling to L. buchneri (> $30 \%)$ after $60 \mathrm{~d}$ of ensiling. However, no differences were observed on the main bacterial community compositions between BA- and BS-inoculated silages and control.

Due to the low relative abundance of Bacillus, we only annotated Bacillus at the genus levels, but did not annotated B. amyloliquefaciens and B. subtilis at the species levels in this study. Therefore, we performed a statistical analysis on the relative abundance of Bacillus (Table 4). We found that Bacillus was not detected in the fresh 
Table 2 Fermentation characteristics of the whole-plant corn silage during ensiling

\begin{tabular}{|c|c|c|c|c|c|c|c|c|c|c|c|}
\hline \multirow[t]{2}{*}{ Items } & \multirow[t]{2}{*}{ Treatment $^{1}$} & \multicolumn{5}{|c|}{$D^{2}, d$} & \multirow[t]{2}{*}{ Mean } & \multirow[t]{2}{*}{ SEM $^{3}$} & \multicolumn{3}{|c|}{$P$-value ${ }^{4}$} \\
\hline & & 1 & 3 & 7 & 14 & 60 & & & $\mathrm{~T}$ & D & $T \times D$ \\
\hline \multirow[t]{3}{*}{$\mathrm{pH}$} & CK & 4.24 & 4.04 & 4.04 & 4.09 & 3.98 & 4.08 & 0.002 & $<0.001$ & $<0.001$ & $<0.001$ \\
\hline & BA & 4.23 & 4.04 & 4.03 & 4.00 & 3.95 & 4.05 & & & & \\
\hline & BS & 4.23 & 4.04 & 4.01 & 4.01 & 3.98 & 4.05 & & & & \\
\hline \multirow[t]{3}{*}{ lactic acid, g/kg DM } & CK & 11.3 & 22.9 & 37.8 & 48.4 & 63.0 & 36.9 & 0.52 & $<0.001$ & $<0.001$ & $<0.001$ \\
\hline & BA & 16.5 & 25.7 & 48.4 & 75.7 & 72.7 & 47.8 & & & & \\
\hline & BS & 16.7 & 29.3 & 45.9 & 54.1 & 67.9 & 42.8 & & & & \\
\hline \multirow[t]{3}{*}{ Acetic acid, g/kg DM } & CK & 4.26 & 8.57 & 17.0 & 25.3 & 34.6 & 18.0 & 0.09 & $<0.001$ & $<0.001$ & $<0.001$ \\
\hline & BA & 6.67 & 9.35 & 21.0 & 23.2 & 29.4 & 17.9 & & & & \\
\hline & BS & 5.73 & 10.2 & 21.6 & 26.4 & 34.9 & 19.8 & & & & \\
\hline \multirow[t]{3}{*}{ Lactic acid/Acetic acid ratio } & CK & 2.55 & 2.67 & 2.31 & 1.93 & 2.07 & 2.31 & 0.009 & $<0.001$ & $<0.001$ & $<0.001$ \\
\hline & BA & 2.81 & 2.75 & 2.38 & 1.95 & 2.03 & 2.38 & & & & \\
\hline & BS & 2.88 & 2.99 & 2.37 & 1.99 & 2.06 & 2.46 & & & & \\
\hline
\end{tabular}

${ }^{1} C K$, control, no inoculations; $B A$, silages inoculated with Bacillus amyloliquefaciens; $B S$, silages inoculated with Bacillus subtilis

${ }^{2} D$, Ensilage time

${ }^{3} S E M$, standard error of the mean

${ }^{4} T$, inoculants treatment; $\mathrm{D}$, fermentation time; $T \times D$, the interaction between inoculants treatment and fermentation time

sample and control. The higher relative abundance of Bacillus was observed in BS-inoculated silage than that in BA-inoculated silage. In addition, the relative abundance of Bacillus in BS-inoculated silage was increased with the extension of ensiling time, while the relative abundance of Bacillus kept stable during the entire ensiling period.

Then we explored the differences in bacterial communities among the three groups using the LEfSe analysis (Fig. 2). After $1 \mathrm{~d}$ of ensiling, the Chloroplast, and Acetobacter were higher in control, while Bacillus and Rhodococcus were higher in BS-inoculated silage, and Lactobacillales and Bacilli were high in BA-inoculated

Table 3 Chemical compositions of the whole-plant corn silage after $60 \mathrm{~d}$ of ensiling

\begin{tabular}{|c|c|c|c|c|c|}
\hline \multirow[t]{2}{*}{ Items $^{1}$} & \multicolumn{3}{|c|}{ Treatments $^{2}$} & \multirow[t]{2}{*}{ SEM $^{3}$} & \multirow{2}{*}{$\begin{array}{l}P \text { - } \\
\text { value }\end{array}$} \\
\hline & $\overline{C K}$ & BA & BS & & \\
\hline $\mathrm{DM}, \mathrm{g} / \mathrm{kg}$ & 27.4 & 28.1 & 28.1 & 0.25 & 0.405 \\
\hline WSC, g/kg DM & $159^{b}$ & $186^{\mathrm{a}}$ & $181^{\mathrm{a}}$ & 4.5 & 0.002 \\
\hline Starch, g/kg DM & $94.3^{\mathrm{a}}$ & $62.5^{\mathrm{b}}$ & $75.5^{\mathrm{b}}$ & 0.51 & 0.005 \\
\hline$C P, g / k g ~ D M$ & $84.0^{\mathrm{b}}$ & $82.2^{c}$ & $85.3^{\mathrm{a}}$ & 0.46 & $<0.001$ \\
\hline NPN, g/kg total N & $97.3^{b}$ & $144.1^{\mathrm{a}}$ & $92.0^{c}$ & 8.29 & $<0.001$ \\
\hline $\mathrm{NH}_{3}-\mathrm{N}, \mathrm{g} / \mathrm{kg}$ total $\mathrm{N}$ & 68.2 & 61.5 & 68.4 & 1.55 & 0.097 \\
\hline aNDF, g/kg DM & $481^{a}$ & $478^{a}$ & $468^{b}$ & 0.2 & $<0.001$ \\
\hline$A D F, g / k g ~ D M$ & $252^{\mathrm{a}}$ & $248^{\mathrm{a}}$ & $235^{b}$ & 0.3 & $<0.001$ \\
\hline
\end{tabular}

a-c Means within a row without a common superscript letter differ ${ }^{1} D M$, dry matter; WSC, water soluble carbohydrates; $C P$, crude protein; NPN, non-protein nitrogen; $\mathrm{NH}_{3}-\mathrm{N}$, ammonia nitrogen; $a N D F$, neutral detergent fiber assayed with a heat stable amylase and expressed inclusive of residual ash; $A D F$, acid detergent fiber expressed inclusive of residual ash

${ }^{2} C K$, control, no inoculations; $B A$, silages inoculated with Bacillus amyloliquefaciens; $B S$, silages inoculated with Bacillus subtilis

${ }^{3} S E M$, standard error of the mean silage. After $3 \mathrm{~d}$ of ensiling, the significantly different bacteria were all lactic acid bacteria (LAB) among the three groups, Leuconostoc was in control, Lactobacillus was in BA-inoculated silage. Bacillus was higher in BSinoculated silages after 7,14, and $60 \mathrm{~d}$ of ensiling period. Acinetobacter and Acetobacter were higher in control than that in BA- and BS-inoculated silages after 14 and $60 \mathrm{~d}$ of ensiling, respectively. Lactobacillales was still higher in BA-inoculated silage than that in the other two groups after $60 \mathrm{~d}$ of ensiling period.

\section{Bacterial metabolic functions and enzyme shifts during ensiling}

The potential functions and enzyme of bacterial communities of the three groups at different ensiling stages were predicted by the PICRUSt2 software (Fig. 3 and 4). The heat-map of the top 25 predicted functional abundance is shown in Fig. 3A. During the ensiling, the ensiling process was clustered into three categories according to the changes of bacterial functions, namely silages ensiled for 1 and $3 \mathrm{~d}, 7$ and $14 \mathrm{~d}$, and $60 \mathrm{~d}$. The majority of predicted functions explained with KEGG pathways were grouped into cellular processes (4 pathways), environmental information processing (2 pathways), genetic information processing (3 pathways), human diseases (5 pathways), and metabolism (10 pathways) in the three silage groups (Fig. 3B). Among them, carbohydrate metabolism, amino acid metabolism, nucleotide metabolism, and metabolism of cofactors and vitamins were chosen as main metabolic pathways due to their relative abundance accounted for more than 5\% during the whole ensiling process. The relative abundances of nucleotide metabolism and carbohydrate metabolism of the 


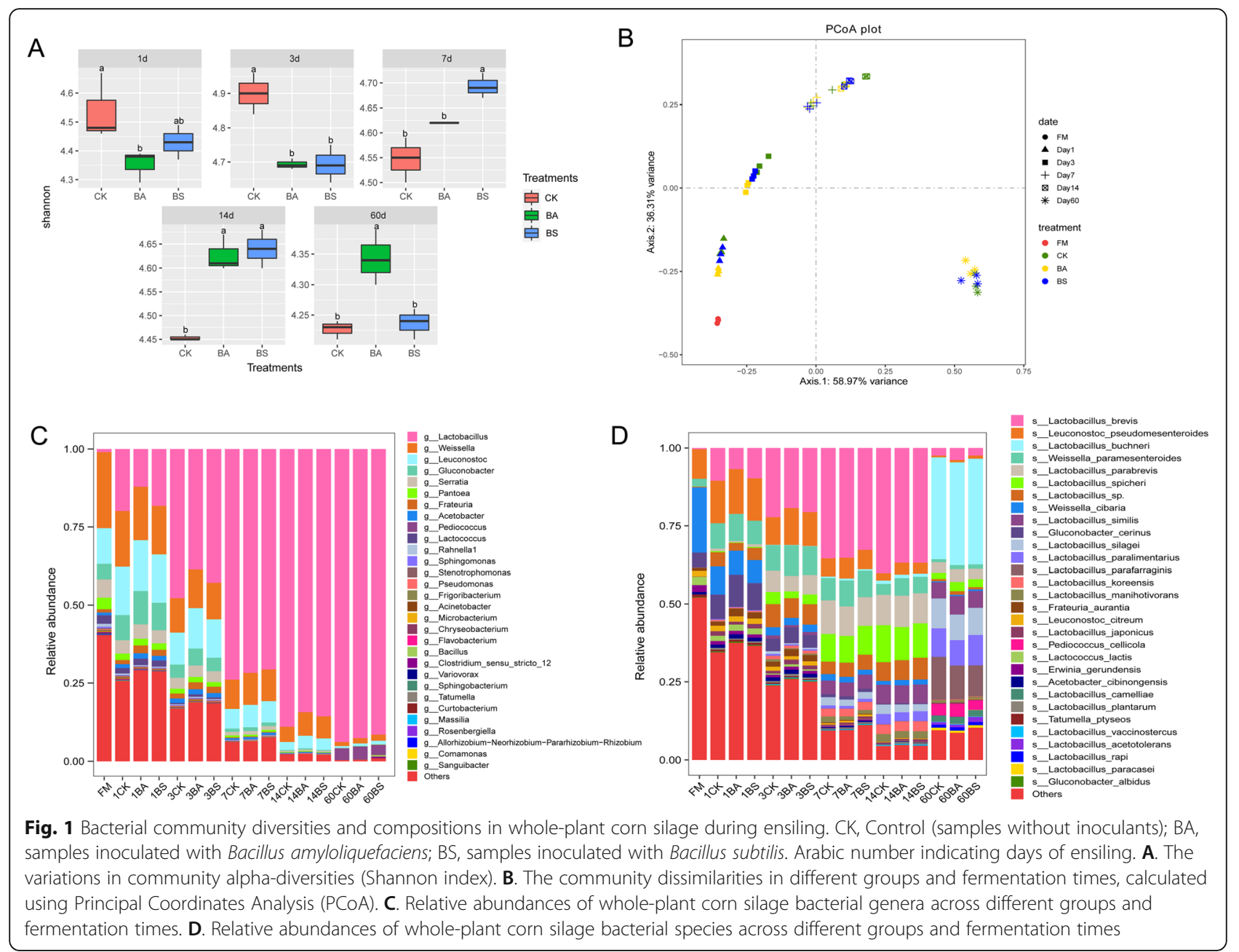

three silage groups increased with the extension of ensiling period. The relative abundances of amino acid metabolism and metabolism of cofactors and vitamins decreased at the stages of 1 to $14 \mathrm{~d}$ of ensiling period, while increased after 60 of ensiling period. In addition, the drug resistance: antimicrobial pathway was the main human disease pathway associated with the silage bacteria. Then the 5 function abundances were analyzed by statistical analysis (Fig. 3C). The higher relative abundances of amino acid and cofactors and vitamins metabolism were observed in BA-inoculated silages compared with control after 1, 3, 7, and $14 \mathrm{~d}$ of ensiling period, while decreased after $60 \mathrm{~d}$ of ensiling period. The relative abundances of carbohydrate metabolism were higher in control compared with BA- and BS-inoculated silages after 1 and $3 \mathrm{~d}$ of ensiling period, while the relative abundance of carbohydrate metabolism increased in the BA- and BS-inoculated silages after $7 \mathrm{~d}$ of ensiling period. The abundances of nucleotide metabolism were higher in control than that in BA- and BS- inoculated silages during the whole ensiling process except after $14 \mathrm{~d}$ of ensiling period. It is noteworthy that the lowest abundance of drug resistance: antimicrobial pathway was in the BA inoculated silage, followed by the BS inoculated silage.

EC:3.2.1.1 ( $\alpha$-amylase), EC:3.2.1.4 (cellulase) and EC: 3.4.21.107 (peptidase) that are closely related to silage fermentation were chosen in enzyme classification (EC) database (Fig. 4). Overall, abundances of $\alpha$-amylase and cellulase of whole-plant corn silage with or without inoculations decreased with the extension of ensiling time (Fig. 4A and C), while peptidase abundance decreased during ensiling period from 7 to $14 \mathrm{~d}$ and then increased after $60 \mathrm{~d}$ of ensiling (Fig. 4B). The abundance of $\alpha$ amylase was higher in BA-inoculated silage when compared with control during the entire ensiling periods. Higher abundance of peptidase was observed in BAinoculated silages compared with that in control and BSinoculated silages during the ensiling periods from 1 to $7 \mathrm{~d}$, while decreased in BA-inoculated silage after $60 \mathrm{~d}$ of ensiling. The abundance of cellulase was higher in BA- and BS-inoculated silage than that in control after 


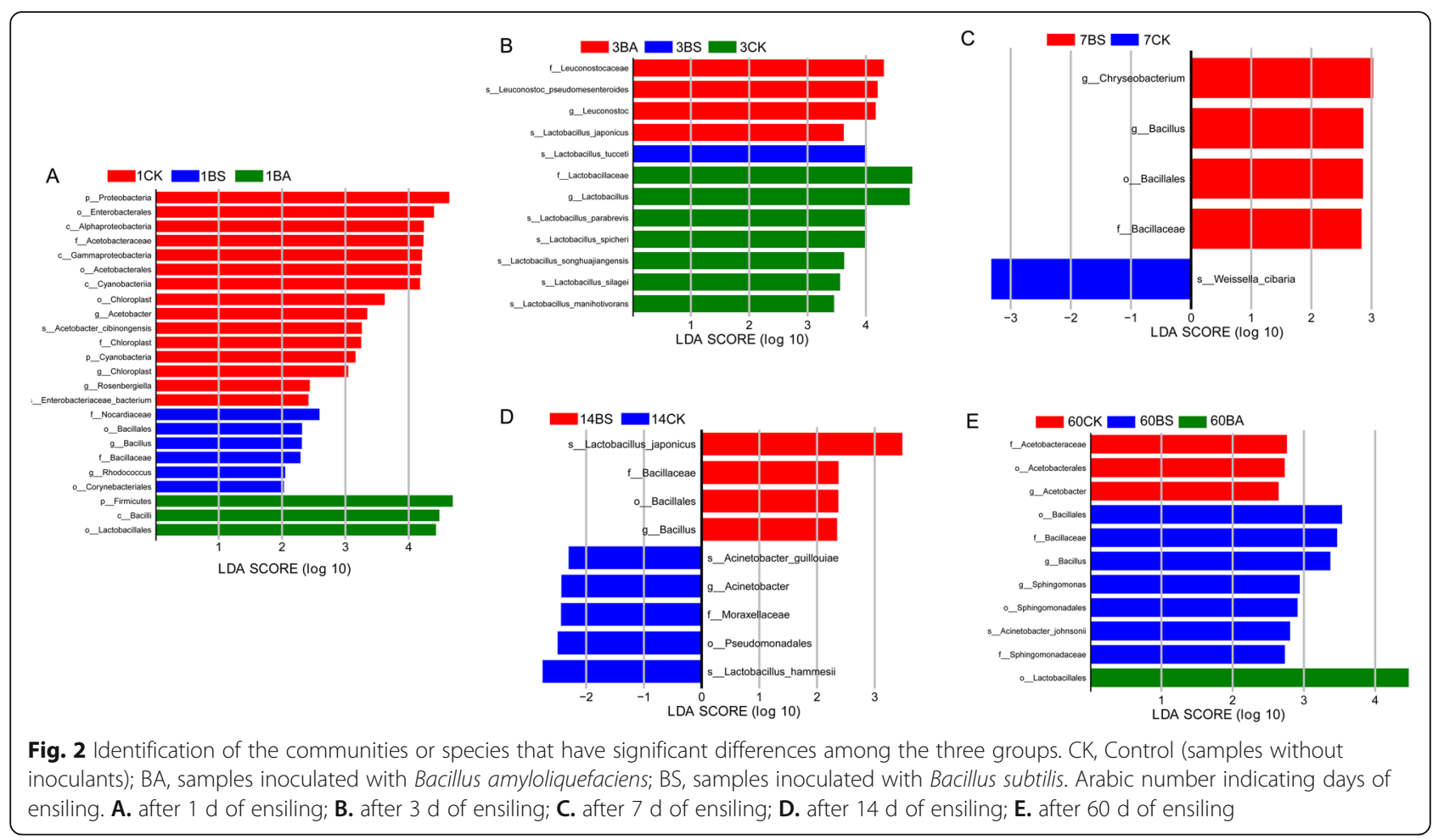

1,3 , and $14 \mathrm{~d}$ of ensiling, while no differences of cellulase abundance were observed between control and inoculated silages after $60 \mathrm{~d}$ of ensiling.

\section{Discussion}

The highest lactic acid concentration was observed in BA-inoculated silage, and the lactic acid concentration of BS-inoculated silage was slightly higher compared with control during ensiling period, which might be explained that BA- and BS-inoculations accelerated lactic acid fermentation during ensiling. According to Guo et al. [14], applying Lactobacillus buchneri accelerated the lactic acid-producing bacteria $L$. plantarum growth to some extent. In addition, it is interesting that the increase in lactic acid concentrations did not cause a

Table 4 Relative abundance of Bacillus during ensiling

\begin{tabular}{llllll}
\hline $\mathbf{D}^{1} \mathbf{d}^{\prime}$ & \multicolumn{2}{l}{ Treatments $^{2}$} & SEM $^{3}$ & $\begin{array}{l}\boldsymbol{P} \text { - } \\
\text { value }\end{array}$ \\
\cline { 2 - 4 } & CK & BA & BS & & \\
\hline 1 & $0^{\mathrm{c}}$ & $0.0104^{\mathrm{b}}$ & $0.057^{\mathrm{a}}$ & 0.0088 & $<0.001$ \\
3 & $0^{\mathrm{c}}$ & $0.0137^{\mathrm{ab}}$ & $0.0259^{\mathrm{a}}$ & 0.0046 & 0.033 \\
7 & $0^{\mathrm{b}}$ & $0.0104^{\mathrm{b}}$ & $0.0587^{\mathrm{a}}$ & 0.0093 & $<0.001$ \\
14 & $0^{\mathrm{b}}$ & $0.0104^{\mathrm{b}}$ & $0.0466^{\mathrm{a}}$ & 0.0075 & 0.002 \\
60 & $0^{\mathrm{b}}$ & $0.0104^{\mathrm{b}}$ & $0.4664^{\mathrm{a}}$ & 0.0771 & $<0.001$ \\
\hline
\end{tabular}

${ }^{a-c}$ Means within a row without a common superscript letter differ ${ }^{1} D$, Ensilage time

${ }^{2} C K$, control, no inoculations; $B A$, silages inoculated with Bacillus amyloliquefaciens; $B S$, silages inoculated with Bacillus subtilis

${ }^{3} S E M$, standard error of the mean decrease in $\mathrm{pH}$ of BA- and BS-inoculated silages. Little differences were observed in $\mathrm{pH}$ between the control and inoculated silages in value in the present study. In our previous study, higher concentrations of lactic acid and $\mathrm{NH}_{3}-\mathrm{N}$, and higher $\mathrm{pH}$ were all in Enterococcus faecalis inoculated silage. Thus, we speculated that $\mathrm{NH}_{3}-\mathrm{N}$ neutralized the acid to prevent the decrease of the $\mathrm{pH}$ value [16]. However, no differences in $\mathrm{NH}_{3}-\mathrm{N}$ contents were observed among the three silage groups, so the possibility that $\mathrm{NH}_{3}-\mathrm{N}$ neutralized acid was ruled out in this study. Therefore, it is hard to explain the phenomenon that the differences of the lactic acid contents were observed while no differences were found in $\mathrm{pH}$ between the control and inoculated silages. The acetic acid concentration was higher in BS-inoculated silage compared with control during the ensiling period from 1 to $14 \mathrm{~d}$, but no difference was observed between control and BS-inoculated silage after $60 \mathrm{~d}$ of ensiling. Similar results also reported in our previous study that BS-inoculation increased the lactic acid concentrations but have no effect on the acetic acid concentrations of alfalfa silage when compared with the control after $60 \mathrm{~d}$ of ensiling [6]. The BA-inoculation increased acetic acid concentration during the ensiling period from 1 to $7 \mathrm{~d}$ when compared with control, while decreased from the ensiling periods from 14 to $60 \mathrm{~d}$. It might be indicated that the BA strain used in this study accelerated lactic acid fermentation, while inhibited acetic acid fermentation of whole-plant corn silage. Kung et al. [26] reported 

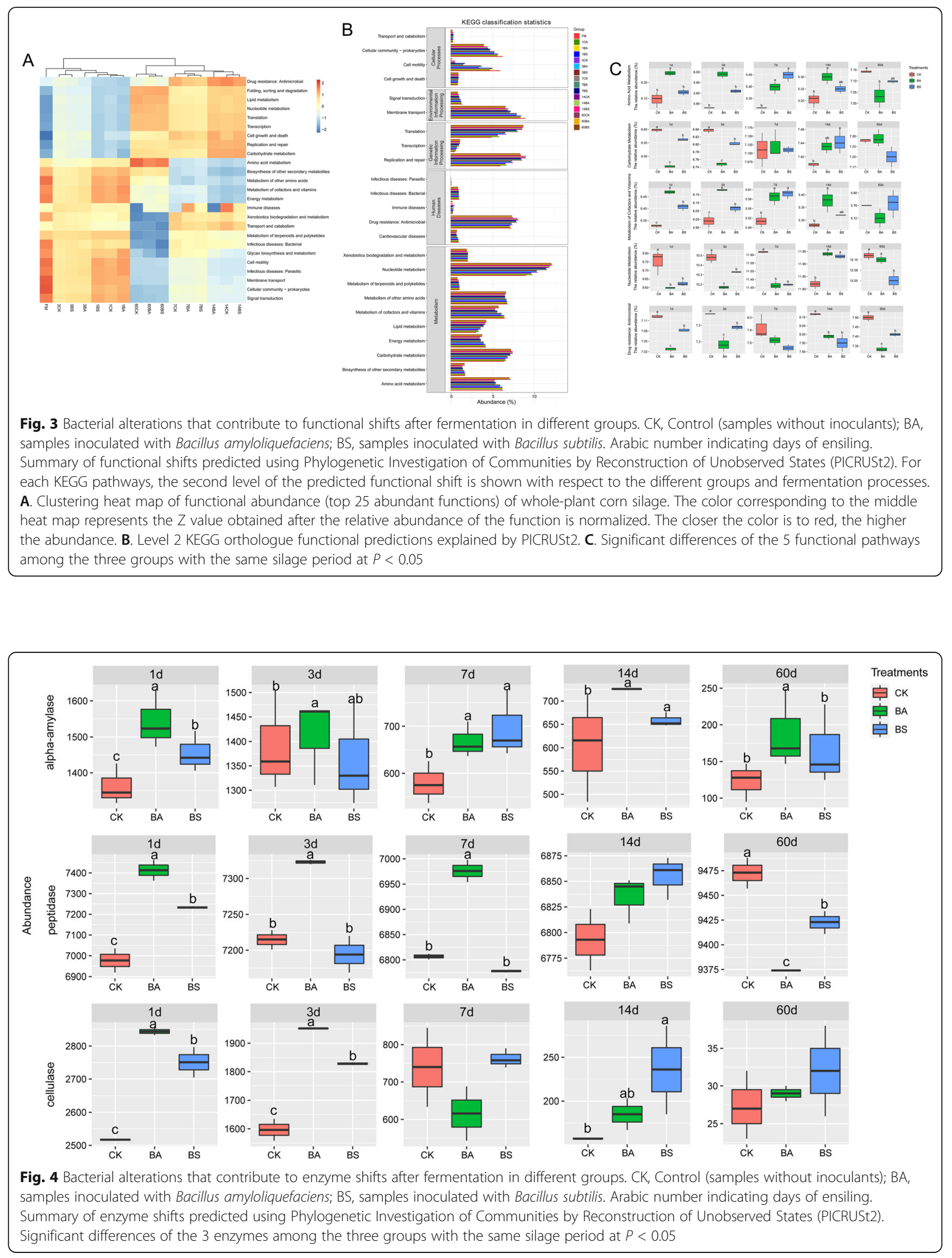
that the LA/AA ratio was commonly used as a qualitative indicator of fermentation, and great fermentation of silages have LA/AA ratio of about 2.5 to 3.0. In the present study, the LA/AA ratio in the three groups decreased to less than 2.5 during 7 to $60 \mathrm{~d}$ of ensiling processes. In addition, Muck and Kung [27] pointed that a slightly higher LA/AA ratio was observed in silages inoculated with homolactic acid inoculants, which might be explained by the only lactic acid produced by homolactic LAB. We found that slightly higher ratios of LA/AA were observed in BA- and BS-inoculated silages during the stages of 1 to $14 \mathrm{~d}$ of ensiling, indicating that the BA and BS inoculations accelerated the homolactic acid bacteria in silages when the fermentation initiated.

The WSC is the critical component for LAB fermentation to produce high-quality silages [28]. Higher WSC contents were observed in BA- and BS-inoculated silages after $60 \mathrm{~d}$ of ensiling period in this study. Meanwhile, we found that the contents of starch were lower in BA- and BS-inoculated silages. Kleinschmit and Kung [29] reported that L. buchneri inoculation reduced WSC contents of grass and small-grain silages compared with the silage without inoculations by a meta-analysis study. Our previous study also showed that L. buchneri and BS inoculations decreased WSC contents of alfalfa silages compared with control [6]. Considering the differences of WSC and starch contents between the control and inoculated silages in the present study, the degradation of starch is probably the result of enzyme mechanisms by the Bacillus inoculation. To confirm this hypothesis, we used the hydrolysis transparent circle method to verify and found that a transparent circle was produced when BA was inoculated on a plate containing soluble starch. Therefore, the BA strain produced amylase to degrade the starch to WSC during ensiling in the present study. According to the previous studies, starch and hemicelluloses could be degraded into simple carbohydrates by microbial and plant enzymes under acidic conditions $[30,31]$. However, starch which generally accounts for $60-80 \%$ of ruminant diets, is the main energy source for the organism and rumen microbes [32]. The massive degradation of starch in whole-plant corn silage is an energy loss for ruminants, even though higher residual WSC degraded by starch in the silage is nutritionally desirable for ruminants. Thus, from the perspective of starch preservation in corn silage, the strains of BA and BS were not suitable for use as whole-plant corn silage inoculants. However, when feeding corn grains to ruminants, the degradation rate of corn starch in the rumen is only $62 \%$ [33]. On the other hand, the fermentation of excessive starch in the rumen will cause changes in the rumen environment, affecting the utilization of other nutrients, and even metabolic diseases. More and more researches have focused on the solid-state fermented feed by Bacillus in livestock production [10, 11]. Therefore, the BA and BS inoculations could be used as inoculants of solid-fermented corn to investigate the effect of rumen starch degradation in further study. The highest $\mathrm{CP}$ content was in BS-inoculated silage, followed by control, and the last was the BA-inoculated silage. On the contrary, the highest NPN content was in BA-inoculated silage, followed by control, and the last was the BSinoculated silage. The result supported in our previous study indicated that the BS inoculation inhibited the proteolysis in alfalfa silage [6]. However, the BA inoculation hydrolyzed CP into large amounts of NPN in the present study. We knew that NPN in the silage was less efficiently synthesized by rumen microbial nitrogen than true protein [34]. Although the inoculation of BA increased the loss of true protein, the proteases metabolized by BA might help increasing starch digestibility. According to Kotarski et al. [35], the exposed endosperm could not be fully digested as the existence of a starchprotein matrix formed in the chemical bonding of zein protein with starch granules. Therefore, the zein protein might be hydrolyzed by protease to release starch granules, which facilitated the hydrolysis of starch by amylase, which might be explained by the lowest starch content in BA-inoculated silage. Then we confirmed that the BA strain produced protease to degrade protein by using the hydrolysis transparent circle method that a transparent circle was produced when BA was inoculated on a plate containing casein. The reduced contents of aNDF and ADF were in BS-inoculated silage when compared with control after $60 \mathrm{~d}$ of ensiling, which was consistent with our previous study that BS inoculation decreased aNDF and ADF contents in alfalfa silage [6]. However, the BA inoculation did not have the ability to degrade aNDF and ADF.

No difference was observed in bacterial diversity of whole-plant corn silages with the extension of ensiling time according to the Shannon index in the present study. However, Xu et al. [17] showed that the decreased alpha diversity was observed when the compositions of dominant $\mathrm{LAB}$ became relatively simple during ensiling. In the present study, complete changes were observed in the compositions of the dominant bacterial species during the ensiling of the corn silage, but the compositions did not become simple. This might be the explanation of alpha diversity kept stable during the entire ensiling process. The bacterial Shannon index (alpha diversity) was higher in control compared with that of BA- and BS-inoculated silages during the ensiling period from 1 to $3 \mathrm{~d}$, while the Shannon index decreased in control compared with BA- and BS-inoculated silages from 7 to $60 \mathrm{~d}$ of ensiling. It was probably due to the antibacterial substance produced by the strains BA and BS during the early ensiling period that inhibited the growth of 
undesirable microorganisms, and consequently decreased bacterial diversity. The beta diversity analysis revealed a significant temporal and regular succession pattern among the ensiling stages, identifying that ensiling time as a factor which shaped the differences of whole-plant corn microorganism during the ensiling period. In addition, the bacteria of silages fermented for 7 and $14 \mathrm{~d}$ clustered together, indicating that there was little change in bacterial diversity of whole-plant corn silage during ensiling period from 7 to $14 \mathrm{~d}$. However, the bacterial diversity was indistinguishable among control and silages inoculated with BA or BS, which was in accordance with the report of Xu et al. [17] that L. plantarum and L. buchneri inoculations did not clearly separate bacterial diversity of whole-plant corn silage compared with control.

To future reveal the bacterial community compositions of whole-plant corn silage inoculated with the strains of BA and BS, we evaluated bacterial communities at genus and species level. The relative abundances of Lactobacillus increased gradually during the entire ensiling process. Lactobacillus, rod-shaped LAB, plays a predominant role in lactic acid fermentation in silages [36]. Guan et al. [37] reported that Lactobacillus dominated in the early stages of corn ensiled without silage inoculants. However, Lactobacillus dominated in the entire stage of ensiling, especially during 7 to $60 \mathrm{~d}$ of ensiling in this study, which was in accordance with the report of $\mathrm{Ni}$ et al. [38] that Lactobacillus played crucial roles in $\mathrm{pH}$ decrease at the later stage of ensiling. The compositions of the dominant bacteria in the three groups were similar, but the relative abundances had certain degrees of differences. The relative abundances of Weissella, Leuconostoc, Gluconobacter, and Serratia were also higher in whole-plant corn silages after $1 \mathrm{~d}$ of ensiling except Lactobacillus. The relative abundances of the four genera decreased with the extension of ensiling until they were completely replaced by Lactobacillus and Pediococcus after $60 \mathrm{~d}$ of ensiling period. In addition, species of Lactobacillus also underwent a complete change that L. brevis, L. parabrevis, L. spicheri, and $L$. similis at the stages of 1 to $14 \mathrm{~d}$ of ensiling completely changed to L. buchneri, L. silagei, L. paralimentarius, and $L$. parafarraginis after $60 \mathrm{~d}$ of ensiling. Furthermore, we found that BA and BS inoculations increased the relative abundances of Leuconostoc pseudomesenteroides and Weissella paramesenteroides of whole-plant corn silage compared with control, which might explain the increased lactic acid concentrations in BA- and BSinoculated silages. Leuconostoc and Weissella as lacticacid-producing cocci initiated lactic fermentation during the stages of early ensiling, while they had lower tolerance to low $\mathrm{pH}$ than Lactobacillus [38, 39]. Additionally, we found that the BS inoculation promoted the growth of Weissella in alfalfa silage in our previous study [6]. The strain Gluconobacter cerinus and their role in silage fermentation were not reported in previous studies. The genus Gluconobacter, which belongs to the group of acetic acid bacteria, is the most important producer of wine spoilage which is legally defined by volatile acidity, largely composed of acetic acid [40, 41]. Therefore, the increased acetic acid concentration in BA-inoculated silage during the ensiling period from 1 to $7 \mathrm{~d}$ might be due to the higher relative abundance of $G$. cerinus. The acetic acid concentrations of BA-inoculated silage decreased from 14 to $60 \mathrm{~d}$ of ensiling when the growth of the aerobic bacteria Gluconobacter was inhibited by the anaerobic environment [40]. The BA and BS inoculations, unlike the Lactobacillus inoculation, had little effect on the bacterial community of whole-plant corn silage. $\mathrm{Xu}$ et al. [2] reported that the Saccharomyces cerevisiae inoculation, a kind of facultative aerobic fungus, had little effect on the bacterial community composition of whole-plant corn during ensiling. While according to $\mathrm{Xu}$ et al. [17], L. plantarum or L. buchneri inoculations resulted in significant differences in bacterial community composition as well as their succession when compared with control in ensiled corn. It might indicate that Bacillus and S. cerevisiae as unconventional silage inoculations, had a weak competition with the epiphytic microorganisms of whole-plant corn raw materials, especially with the progress of anaerobic ensiling process, they were not enough to change the bacterial community compositions of corn silage.

In order to explore the dynamics of BA and BS additives in the whole-plant silage during ensiling, we performed statistical analysis on the relative abundance of Bacillus. Because of we only annotated Bacillus at the genus levels, but did not annotated B. amyloliquefaciens and $B$. subtilis at the species levels in this study. We found that the relative abundance of Bacillus was zero in the fresh sample and control during the entire ensiling, indicating that Bacillus was not present in the wholeplant corn silage that is naturally fermented in the present study. Therefore, the Bacillus detected in BAand BS-inoculated silages should be the added ones. In addition, we found that the higher relative abundance of Bacillus was observed in BS-inoculated silage than that in BA-inoculated silage. Meanwhile, the relative abundance of Bacillus in BS-inoculated silage was increased with the extension of ensiling time. The result indicated that as facultative aerobic bacteria, the B. subtilis strain had higher activity and adaptability in whole-plant corn silage than the $B$. amyloliquefaciens strain in the present study.

To further explore the differences of bacterial community between control and BA- and BS-inoculated silages, we used LEfSe analysis which is a method that coupled 
standard tests for statistical significance with additional tests encoding biological consistency and effect relevance [42]. Bacillus was the most differentially abundant bacteria in the BS-inoculated whole-plant corn silage during the entire ensiling procedure except for $3 \mathrm{~d}$ of ensiling. The same result was obtained in our previous study that Bacillus was significantly higher in BS-inoculated alfalfa silage than that in control after $60 \mathrm{~d}$ of ensiling by LEfSe analysis [6]. It was inferred that Bacillus could also grow in silages with anaerobic fermentation. However, Bacillus did not increase significantly in BA-inoculated silage. It does not mean that Bacillus was not present in BAinoculated silage. In addition, Lactobacillales was significantly higher in BA-inoculated silage than that in control and BS-inoculated silage by LEfSe analysis after 1 and $60 \mathrm{~d}$ of ensiling, and Leuconostoc was the most differentially abundant bacteria in BA-inoculated silage after $3 \mathrm{~d}$ of ensiling, which might be explained by the higher lactic acid concentrations in BA-inoculated silage. Acetobacter and Acinetobacter, undesirable bacteria in silages, were the most differentially abundant bacteria in control during ensiling, indicating that BA and BS inoculations could inhibit the growth of undesirable bacteria of silage.

The ensiling process is mediated by microbial metabolic pathways to transform metabolites or degrade substrates. We can assess the effect of bacterial communities on the changes in the metabolic pathways during ensiling by predicting bacterial functions. Therefore, the KEGG pathway database with PICRUSt2 was used to predict the bacterial community functions of whole-plant corn silages in this study. We found that the silage fermentation process was clustered into three groups according to the changes of bacterial functions, which could be used to define stages of silage fermentation as early ( 1 to $3 \mathrm{~d}$ of ensiling), mid ( 7 to $14 \mathrm{~d}$ of ensiling), and late (60 d of ensiling) periods. We generally focused on the metabolism of carbohydrates, nucleotide, energy, amino acid and cofactors and vitamins (the main metabolic pathways in silages), which were related to the changes of fermentation and chemical characteristics $[16,17]$. In the present study, carbohydrate and nucleotide metabolism of the three silage groups increased with the extension of ensiling. According to Bai et al. [16], the relative abundances of total LAB in the microbial community affected the abundances of carbohydrate metabolism pathway. The increased total LAB abundance was also observed in silages with higher carbohydrate metabolism pathway abundances the present study. According to the report of Kilstrup et al. [43], most of metabolic reactions are related to either bacterial utilization of nucleotides or their regulation by metabolites. Silage fermentation was dominated by LAB, therefore, increases in the total LAB abundance might lead to the enhancement of nucleotide metabolism. The higher relative abundances of nucleotide metabolism were observed in control than that in BA- and BS-inoculated silages during the entire ensiling periods except $14 \mathrm{~d}$ of ensiling, which might be due to the slightly higher relative abundance of total dominant LAB in the control. Metabolism of amino acid and cofactors and vitamins decreased during the phases from 1 to $14 \mathrm{~d}$ of ensiling period while increased after $60 \mathrm{~d}$ of ensiling period. It was hard to explain the reason for this phenomenon. The higher relative abundances of metabolism of cofactors and vitamins were observed in BA- and BSinoculated silages. In our previous study, the Enterococcus faecalis inoculation increased relative abundance of metabolism of cofactors and vitamins in alfalfa silage [16]. It might be inferred that some strains of Bacillus could accelerate vitamin production or produce vitamins directly during ensiling. In addition, the amino acid metabolism increased in BA-inoculated silage compare to control during the phases from 1 to $14 \mathrm{~d}$ of ensiling, which was in accordance with the decreased $\mathrm{CP}$ content and increased NPN content in BA-inoculated silage. That might be the result of protein degradation by the proteases produced by the BA strain.

The abuse of antibiotic results a global growth of multidrug-resistant bacteria, which becomes one of the greatest threats to human health. [44]. In nature, antibiotic-resistance genes exist in bacterial and fungal [45]. Therefore, we chose the drug resistance: antimicrobial pathway to explore the changes of this pathway during ensiling process and the differences among the three groups. The relative abundances of the drug resistance: antimicrobial pathway increased during the 1 to $14 \mathrm{~d}$ phase of the ensiling period, while decreased after $60 \mathrm{~d}$ of ensiling period. Meanwhile, the highest relative abundances of this pathway were observed in control during the entire ensiling process, and the lowest relative abundances were in BA-inoculated silage, followed by BSinoculated silage. The antimicrobial drug resistances are mostly found in the undesirable bacteria, such as Salmonella and Escherichia coli $[46,47]$. It might be due to the antibacterial substance produced by BA and BS inoculations that inhibit the growth of undesirable and harmful bacteria and thus reduced the resistance genes.

In order to further confirm the effects of BA and BS inoculants on the chemical characteristics of wholeplant corn silages, EC numbers of $\alpha$-amylase, peptidase and cellulase were chosen according to PICRUSt2 in this study. We found that the highest abundance of $\alpha$ amylase was observed in BA-inoculated silage during the entire ensiling period, which was consistent with the lowest content of starch in BA-inoculated silage after 60 $\mathrm{d}$ of ensiling. The lowest abundance of $\alpha$-amylase was in accordance with the highest content starch in control. 
The result indicated that the BA strain in this study produced $\alpha$-amylase to degrade starch during ensiling of whole-plant corn silage. In addition, the BA inoculation increased the abundance of peptidase during the early ensiling periods, while the peptidase abundance became the lowest in BA-inoculated silage after $60 \mathrm{~d}$ of ensiling. The lowest $\mathrm{CP}$ content in BA-inoculated silage might be due to the stronger activity of the facultative aerobe BA strain in the early stage of ensiling, which produced more peptidase in the optimal growth environment. The lower abundance of peptidase was observed in BSinoculated silage compared with BA-inoculated silage, which was consistent with the higher $\mathrm{CP}$ content and lower NPN content in BS-inoculated silage. The changes of cellulase abundance of the three silage groups could not explain the differences in aNDF and ADF contents. We found that the BS inoculation decreased aNDF and ADF contents of whole-plant corn silage compared with control and BA-inoculated silage. However, the cellulase abundance was higher in BA-inoculated silage than that in control and BS-inoculated silage after 1 and $3 \mathrm{~d}$ of ensiling, and no difference on the cellulase abundance was observed between BA- and BS-inoculated silages during the ensiling period from 7 to $60 \mathrm{~d}$. Therefore, the decrease in fiber content in BS-inoculated silage might not be related to the abundance the effect of cellulase.

\section{Conclusions}

The BA and BS inoculations had a little effect on bacterial community compositions. However, BA and BS inoculations significantly decreased the relative abundance of Acetobacter and Acinetobacter according to LEfSe analysis. Higher abundances of Bacillus and Lactobacillales were observed in BS- and BA-inoculated silage, respectively. Additionally, the whole-plant corn ensiling process could be clustered into three stages through changes in metabolism pathways, which could be a new approach to silage research. We also found that BA inoculation increased the relative abundances of amino acid metabolism, which was consistent with the increased NPN content and the decreased CP content in BA-inoculated silage. Meanwhile, the decreased starch content and increased WSC content were observed in BA-inoculated silage after $60 \mathrm{~d}$ of ensiling period. Due to the special digestion and absorption mechanism of ruminants, the degradation of protein and starch by BA might not be suitable for whole-plant corn silage. However, the BS inoculation increased the $\mathrm{CP}$ content and reduced the contents of NPN, aNDF, and ADF when compare with control. It is noteworthy that the metabolism of cofactors and vitamins increased in BA- and BS-inoculated silages; meanwhile, the drug resistance: antimicrobial pathway decreased during the ensiling.

\section{Abbreviations}

BA: Bacillus amyloliquefaciens; BS: Bacillus subtilis; SMRT: Single-molecule realtime sequencing technology; LAB: Lactic acid bacteria; DM: Dry matter; FW: Ffresh weight; CK: Control; NPN: Non-protein nitrogen; $\mathrm{NH}_{3}-\mathrm{N}$ : Ammonia nitrogen; CP: Crude protein; aNDF: Neutral detergent fiber; ADF: Acid detergent fiber; WSC: Water-soluble carbohydrate; LA/AA: Lactic acid/Acetic acid; PCR: Polymerase Chain Reaction; PCoA: Principal Coordinates Analysis; LEfSe: The linear discriminant analysis effect size analysis;

PICRUSt2: Phylogenetic investigation of communities by reconstruction of unobserved states; KEGG: Kyoto encyclopedia of genes and genomes; SPSS: Statistical package for social science

\section{Acknowledgements}

The finacial support of the National Natural Science Foundation of China (No. 31872417) is highly appreciated.

\section{Authors' contributions}

$X G$ contributed to securing financial support, designing the study. JB contributed to do this study, and preparing the first manuscript draft; MF, $Z D, L H$ and $L A$ revised the manuscript draft; WK, MW, DX, ZL, and $Y Z$ performed data collection and statistical analysis. All authors have read and approved the final manuscript.

\section{Authors' information}

${ }^{1}$ State Key Laboratory of Grassland Agro-ecosystems, School of Life Sciences, College of Pastoral Agriculture Science and Technology, Lanzhou University, Lanzhou 730000, China. ${ }^{2}$ Probiotics and Biological Feed Research Centre, Lanzhou University, Lanzhou 730000, China. ${ }^{3}$ Production systems, Natural Resources Institute Finland (Luke), Fl-31600 Jokioinen, Finland. ${ }^{4}$ School of Food Science and Engineering, Shanxi Agricultural University, Taigu 030801, China. ${ }^{5}$ China Animal Agriculture Association, Beijing 100044, China.

\section{Funding}

This work was funded by National Natural Science Foundation of China (project no. 31872417).

\section{Availability of data and materials}

Raw sequencing files and associated metadata have been deposited in NCBI's Sequence Read Archive (SRR14832366-SRR14832413), https://www ncbi.nlm.nih.gov/sra.

\section{Declarations}

Ethics approval and consent participate

No applicable.

\section{Consent for publication}

No applicable.

\section{Competing interests}

The authors declare that they have no competing interests.

\section{Author details}

${ }^{1}$ State Key Laboratory of Grassland Agro-ecosystems, School of Life Sciences, College of Pastoral Agriculture Science and Technology, Lanzhou University, Lanzhou 730000, China. ${ }^{2}$ Probiotics and Biological Feed Research Centre, Lanzhou University, Lanzhou 730000, China. ${ }^{3}$ Production systems, Natural Resources Institute Finland (Luke), Fl-31600 Jokioinen, Finland. ${ }^{4}$ School of Food Science and Engineering, Shanxi Agricultural University, Taigu 030801, China. ${ }^{5}$ China Animal Agriculture Association, Beijing 100044, China.

Received: 22 June 2021 Accepted: 16 November 2021

Published online: 07 January 2022

\section{References}

1. Kolver ES, Roche JR, DMiller D, Densley R. Maize silage for dairy cows. In: Proceedings of the conference-New Zealand Grassland Association; 2001. p. 195-202. https://doi.org/10.33584/jnzg.2001.63.2407.

2. Xu SW, Yang JL, Meng Q, Smiley B, Rutherford W, Wang YX, et al. Impact of saccharomyces cerevisiae and lactobacillus buchneri on microbial 
communities during ensiling and aerobic spoilage of corn silage. J Anim Sci. 2019;97(3):1273-85. https://doi.org/10.1093/jas/skz021.

3. Li FH, Ding ZT, Ke WC, Xu DM, Zhang P, Bai J, et al. Ferulic acid esteraseproducing lactic acid bacteria and cellulase pretreatments of corn stalk silage at two different temperatures: ensiling characteristics, carbohydrates composition and enzymatic saccharification. Bioresour Technol. 2019;282: 211-21. https://doi.org/10.1016/j.biortech.2019.03.022.

4. Zhang YX, Ke WC, Bai J, Li FH, Xu DM, Ding ZT, et al. The effect of Pediococcus acidilactici $\mathrm{J17}$ with high-antioxidant activity on antioxidant, atocopherol, $\beta$-carotene, fatty acids, and fermentation profiles of alfalfa silage ensiled at two different dry matter contents. Anim Feed Sci Technol. 2020; 268:114614. https://doi.org/10.1016/j.anifeedsci.2020.114614.

5. Zhang LY, Ma QG, Ma SS, Zhang JY, Jia R, Ji C, et al. Ameliorating effects of Bacillus subtilis ANSB060 on growth performance, antioxidant functions, and aflatoxin residues in ducks fed diets contaminate with aflatoxins. Toxins. 2017:9(1):1. https://doi.org/10.3390/toxins9010001.

6. Bai J, Xu DM, Xie DM, Wang MS, Li ZQ, Guo XS. Effects of antibacterial peptide-producing Bacillus subtilis and Lactobacillus buchneri on fermentation, aerobic stability, and microbial community of alfalfa silage. Bioresour Technol. 2020;315:123881. https://doi.org/10.1016/j.biortech.202 0.123881 .

7. Arrebola $E$, Jacobs $R$, Korsten L. Iturin A is the principal inhibitor in the biocontrol activity of Bacillus amyloliquefaciens PPCB004 against postharvest fungal pathogens. J Appl Microbiol. 2010;108(2):386-95. https://doi.org/1 0.1111/j.1365-2672.2009.04438.x.

8. Zhao PC, Quan CS, Wang YG, Wang JH, Fan SD. Bacillus amyloliquefaciens Q-426 as a potential biocontrol agent against fusarium oxysporum $\mathrm{f}$. sp. spinaciae. J Basic Microbiol. 2014;54(5):448-56. https://doi.org/10.1002/ jobm.201200414.

9. Shi C, Zhang Y, Yin Y, Wang C, Lu Z, Wang F, et al. Amino acid and phosphorus digestibility of fermented corn-soybean meal mixed feed with and fed to pigs. J Anim Sci. 2017;95(9):3996-4004. https://doi.org/10.2527/ja s.2017.1516.

10. Zhang Y, Shi CY, Wang C, Lu ZQ, Wang FQ, Feng J, et al. Effect of soybean meal fermented with Bacillus subtilis BS12 on growth performance and small intestinal immune status of piglets. Food Agric Immunol. 2018;29(1): 133-46. https://doi.org/10.1080/09540105.2017.1360258.

11. Li Y, Guo BZ, Wu ZK, Wang WW, Li C, Liu GH, et al. Effects of fermented soybean meal supplementation on the growth performance and cecal microbiota community of broiler chickens. Animals. 2020;10(6):1098. https:// doi.org/10.3390/ani10061098

12. Lara EC, Basso FC, De Assis FB, Souza FA, Berchielli TT, Reis RA. Changes in the nutritive value and aerobic stability of corn silages inoculated with Bacillus subtilis alone or combined with Lactobacillus plantarum. Anim Prod Sci. 2016;56(11):1867-74. https://doi.org/10.1071/AN14686.

13. Sansinenea $E$, Ortiz A. Secondary metabolites of soil Bacillus spp. Biotechnol Lett. 2011:33(8):1523-38. https://doi.org/10.1007/s10529-011-0617-5.

14. Guo XS, Ke WC, Ding WR, Ding LM, Xu DM, Wang WW, et al. Profiling of metabolome and bacterial community dynamics in ensiled Medicago sativa inoculated without or with Lactobacillus plantarum or Lactobacillus buchneri. Sci Rep. 2018;8(1):357. https://doi.org/10.1038/s41598-017-18348-0.

15. Zhang C, Gao Z, Shi WC, Li LC, Tian RM, Huang J, et al. Material conversion, microbial community composition and metabolic functional succession during green soybean hull composting. Bioresour Technol. 2020;316:123823. https://doi.org/10.1016/j.biortech.2020.123823.

16. Bai J, Ding ZT, Ke WC, Xu DM, Wang MS, Huang W, et al. Different lactic acid bacteria and their combinations regulated the fermentation process of ensiled alfalfa: ensiling characteristics, dynamics of bacterial community and their functional shifts. J Microbial Biotechnol. 2021;14(3):1171-82. https://doi. org/10.1111/1751-7915.13785

17. Xu DM, Wang N, Rinne M, Ke WC, Weinberg ZG, Da M, et al. The bacterial community and metabolome dynamics and their interactions modulate fermentation process of whole crop corn silage prepared with or without inoculants. J Microbial Biotechnol. 2020;14(2):561-76. https://doi.org/1 $0.1111 / 1751-7915.13623$

18. Qin N, Miao WY, Li X, Hao L. Optimization and stabilization of antifungal protein from Bacillus amyloliquefaciens strain HRH317. Sci Technol Food Industry. 2017;13:130-5. https://doi.org/10.13386/j.issn1002-0306.2017.13.024.

19. Licitra G, Hernandez TM, Van Soest PJ. Standardization of procedures for nitrogen fractionation of ruminant feeds. Anim Feed Sci Technol. 1996;57(4): 347-58. https://doi.org/10.1016/0377-8401(95)00837-3.
20. Ke WC, Ding WR, Xu DM, Ding LM, Zhang P, Li FD, et al. Effects of addition of malic or citric acids on fermentation quality and chemical characteristics of alfalfa silage. J Dairy Sci. 2017;100(11):8958-66. https://doi.org/10.3168/ jds.2017-12875.

21. AOAC. Official methods of analysis. 15th ed. Artington: Association of Officia Analytical Chemists; 1990.

22. Van Soest PJ, Robertson JB, Lewis BA. Methods for dietary fiber, neutral detergent fiber, and nonstarch polysaccharides in relation to animal nutrition. J Dairy Sci. 1991;74(10):3583-97. https://doi.org/10.3168/jds.S00220302(91)78551-2.

23. Ovaskainen O, Nokso-koivisto J, Hottola J, Rajala T, Taina P, Ali-Kovero H, et al. Identifying wood-inhabiting fungi with 454 sequencing - what is the probability that BLAST gives the correct species? Fungal Ecol. 2010;3(4):27483. https://doi.org/10.1016/j.funeco.2010.01.001.

24. Quast C, Pruesse E, Yilmaz P, Gerken J, Schweer T, Yarza P, et al. The SILVA ribosomal RNA gene database project: improved data processing and webbased tools. Nucleic Acids Res. 2013;41(Database issue):590-6. https:// doi.org/10.1093/nar/gks1219.

25. Douglas GM, Maffei VJ, Zaneveld J, Yurgel SN, Brown JR, Taylor CM, et al. PICRUSt2: an improved and customizable approach for metagenome inference. BioRxiv. 2020:672295:1-16. https://doi.org/10.1101/672295.

26. Kung LM, Shaver RD, Grant RJ, Schmidt RJ. Silage review: interpretation of chemical, microbial, and organoleptic components of silages. J Dairy Sci. 2018;101(5):4020-33. https://doi.org/10.3168/jds.2017-13909.

27. Muck RE, Kung L Jr. Effect of silage additives on ensiling. In: Proc. Silage Field to Feedbunk North Am. Conf., Hershey, PA. Ithaca: Northeast Regional Agricultural Engineering Service; 1997. p. 187-210.

28. Rooke JA, Hatfield RD. Biochemistry of ensiling. In: Buxton DR, Muck RE, Harrison HJ, editors. Silage science and technology. Madison: American Society of Agronomy; 2003. p. 95-139. https://doi.org/10.2134/a gronmonogr42.c3.

29. Kleinschmit DH, Kung L Jr. A meta-analysis of the effects of Lactobacillus buchneri on the fermentation and aerobic stability of corn and grass and small-grain silages. J Dairy Sci. 2006;89(10):4005-13. https://doi.org/10.3168/ jds.S0022-0302(06)72444-4.

30. Muck RE. Dry matter level effects on alfalfa silage quality. II. Fermentation products and starch hydrolysis. Trans Am Soc Agric Eng. 1990;33(2):373-81. https://doi.org/10.13031/2013.31340.

31. Dewar WA, McDonald P, Whittenbury R. The hydrolysis of grass hemicelluloses during ensilage. J Sci Food Agric. 1963;14(6):411-7. https:// doi.org/10.1002/jsfa.2740140610.

32. Huntington GB. Starch utilization by ruminants: from base to the bunk. $J$ Anim Sci. 1997;75(3):852-67. https://doi.org/10.2527/1997.753852x.

33. Herrera-Saldana RE, Huber JT, Poore MH. Dry matter, crude protein, and starch degradability of five cereal grains. J Dairy Sci. 1990;73(9):2386-93. https://doi.org/10.3168/jds.50022-0302(90)78922-9.

34. Pahlow G, Muck RE, Driehuis F, Elferink SJWHO, Spoelstra SF. Microbiology of ensiling. Agron Monogr. 2003;42:31-94. https://doi.org/10.2134/a gronmonogr42.c2.

35. Kotarski SF, Waniska RD, Thurn KK. Starch hydrolysis by the ruminal microflora. J Nutr. 1992;122(1):178-90. https://doi.org/10.1093/jn/122.1.178.

36. Nazar M, Wang S, Zhao J, Dong ZH, Li JF, Kaka NA, et al. The feasibility and effects of exogenous epiphytic microbiota on the fermentation quality and microbial community dynamics of whole crop corn. Bioresour Technol. 2020:306:123106. https://doi.org/10.1016/j.biortech.2020.123106.

37. Guan H, Yan YH, Li XL, Li XM, Shuai Y, Feng GY, et al. Microbial communities and natural fermentation of corn silages prepared with farm bunker-silo in Southwest China. Bioresour Technol. 2018;265:282-90. https://doi.org/10.101 6/j.biortech.2018.06.018.

38. Ni KK, Wang FF, Zhu BG, Yang JX, Zhou GA, Pan Y, et al. Effects of lactic acid bacteria and molasses additives on the microbial community and fermentation quality of soybean silage. Bioresour Technol. 2017;238:706-15. https://doi.org/10.1016/j.biortech.2017.04.055.

39. Yang LL, Yuan XJ, Li JF, Dong ZH, Shao T. Dynamics of microbial community and fermentation quality during ensiling of sterile and nonsterile alfalfa with or without Lactobacillus plantarum inoculant. Bioresour Technol. 2019;275:280-7. https://doi.org/10.1016/j.biortech.201 8.12.067.

40. Deppenmeier U, Hoffmeister M, Prust C. Biochemistry and biotechnological applications of Gluconobacter strains. Appl Microbiol Biotechnol. 2002;60(3): 233-42. https://doi.org/10.1007/s00253-002-1114-5. 
41. Bartowsky EJ, Henschke PA. Acetic acid bacteria spoilage of bottled red wine-a review. Int J Food Microbiol. 2008;125(1):60-70. https://doi.org/10.1 016/j.ijfoodmicro.2007.10.016.

42. Segata N, Izard J, Waldron L, Gevers D, Miropolsky L, Garrett WS, et al. Metagenomic biomarker discovery and explanation. Genome Biol. 2011; 12(6):R60. https://doi.org/10.1186/gb-2011-12-6-r60.

43. Kilstrup M, Hammer K, Jensen PR, Martinussen J. Nucleotide metabolism and its control in lactic acid bacteria. FEMS Microbiol Rev. 2005;29(3):555-90. https://doi.org/10.1016/j.fmrre.2005.04.006.

44. Blair JMA, Webber MA, Baylay AJ, Ogbolu DO, Piddock LJV. Molecular mechanisms of antibiotic resistance. Nat Rev Microbiol. 2015;13(1):42-51. https://doi.org/10.1038/nrmicro3380.

45. Bahram M, Hildebrand F, Forslund SK, Anderson JL, Soudzilovskaia NA Bodegom PM, et al. Structure and function of the global topsoil microbiome. Nature. 2018:560(7717):233-7. https://doi.org/10.1038/s41586018-0386-6.

46. Threlfall EJ. Antimicrobial drug resistance in Salmonella: problems and perspectives in food-and water-borne infections. FEMS Microbiol Rev. 2002; 26(2):141-8. https://doi.org/10.1016/S0168-6445(02)00092-X.

47. Tadesse DA, Zhao SH, Tong E, Ayers S, Singh A, Bartholomew MJ, et al. Antimicrobial drug resistance in Escherichia coli from humans and food animals, United States, 1950-2002. Emerg Infect Dis. 2012;18(5):741-9. https://doi.org/10.3201/eid1805.111153.

Ready to submit your research? Choose BMC and benefit from:

- fast, convenient online submission

- thorough peer review by experienced researchers in your field

- rapid publication on acceptance

- support for research data, including large and complex data types

- gold Open Access which fosters wider collaboration and increased citations

- maximum visibility for your research: over $100 \mathrm{M}$ website views per year

At $\mathrm{BMC}$, research is always in progress.

Learn more biomedcentral.com/submissions 